\title{
Expression analysis of individual homoeologous wheat genome- and rye genome-specific transcripts in a 2BS.2RL wheat-rye translocation
}

\author{
Tong Geon Lee ${ }^{1,2 *}$, Yong Jin Lee ${ }^{1}$ and Yong Weon $\mathrm{Seo}^{1 \dagger}$ \\ ${ }^{1}$ Division of Biotechnology, Korea University, Seoul 136-701, Republic of Korea \\ ${ }^{2}$ Current Address: Department of Crop Sciences, University of Illinois, Urbana, IL 61801, USA
}

(Received 19 June 2014, accepted 17 October 2014)

\begin{abstract}
Wheat-rye translocations are widely used in wheat breeding to confer resistance against abiotic and biotic stress. Studying gene expression in wheat-rye translocations is complicated due to the presence of homoeologous genes in hexaploid wheat and high levels of synteny between wheat and rye chromatin. To distinguish transcripts expressed from each of the three wheat genomes and those from rye chromatin, genomic probes generated from diploid progenitors of wheat and rye were synthesized on a custom array. A total of 407 transcripts showed homoeologous genome ('A', 'B' or 'D' genome)- or rye genome ('R')-specific differential expression, based on unequal values of probe hybridization. In a $2 \mathrm{BS} .2 \mathrm{RL}$ wheat-rye translocation, thirteen of the 407 transcripts showed preferential expressions from rye chromatin. As well as quantifying variation in homoeologous transcript in wheat-rye translocations, this study also provides a potential aid to examine the contribution of the subgenomes to complex allohexapolyploids.
\end{abstract}

Key words: polyploidy, homoeologous, wheat-rye translocation, gene expression

\section{INTRODUCTION}

Wheat-rye translocations are widely used in wheat breeding. Various forms of the short arm of rye (Secale cereale) chromosome 1 (1RS) have been introduced to confer disease and pest resistance on wheat (Triticum aestivum) in the form of 1AL.1RS, 1BL.1RS, and 1DL.1RS (Friebe et al., 1996; Graybosch, 2001), and roughly 50\% of the wheat varieties from the International Maize and Wheat Improvement Center (CIMMYT) contain the 1BL.1RS translocation (Kishii et al., 2008). While the 1BL.1RS translocation is the most common wheat-rye translocation due to the resistance it confers, the long arm of rye chromosome 2 (2RL) also carries resistance genes, especially for Hessian fly (Mayetiola destructor Say) biotype L, the most destructive insect to wheat (Hatchett et al., 1993). The advantage of a 2BS.2RL wheat-rye translocation is that wheat chromosome $2 \mathrm{~B}$, unlike 1AS and 1BS, lacks storage protein genes that are essential for bread making quality (Knackstedt et al., 1994; McKendry et al., 2001). 2RL may thus prove useful in wheat breeding (Graybosch, 2001).

Although it is widely known that the rye chromatin

\footnotetext{
Edited by Koji Murai

* Corresponding author. E-mail: agrospel@illinois.edu

$\dagger$ Corresponding author. E-mail: seoag@korea.ac.kr
}

within wheat-rye translocations confers resistance to abiotic and biotic stress, the mechanisms of resistance are unknown. Identification of the transcripts involved in stress response in wheat-rye translocations is crucial to understand the functions of rye chromatin within the wheat genome. DNA hybridization-based arrays are an economical and high-throughput method to screen genome-wide transcript levels. These arrays can be customized to contain probes that specifically differentiate transcripts from different subgenomes. The Affymetrix GeneChip Wheat Genome Array (Affymetrix, USA) is commercially available for verifying wheat gene expression, and has been used for independent studies such as low temperature tolerance gene models (LaudenciaChingcuanco et al., 2011), wheat and rust interactions (Coram et al., 2008), and transcriptome analysis during seed germination (Yu et al., 2014). However, rye chromatin 2RL has been shown to exhibit normal homoeologous relationships with the long arm of wheat chromosome 2B (2BL) (Naranjo and Fernandez-Rueda, 1991; Devos et al., 1995), suggesting that the rye genome is sufficiently similar to that of wheat to permit crosshybridization. Twenty-five orthologous sequences of coding regions from the long arms of homoeologous group 2, cloned from the ' $\mathrm{B}$ ' genome diploid progenitor of hexaploid wheat and the diploid rye, show $97 \%$ overall sequence identity (Lee et al., 2010). Thus, homoeologous relation- 
ships among wheat and rye chromatins might cause cross-hybridization of their transcripts on Wheat Genome Array probes, indicating a potential difficulty for distinguishing species-specific transcripts as discussed by Lee et al. (2013).

In this study, we investigate variation in genomespecific transcript abundance in a wheat-rye translocation. Probes were chosen based on sequences unique to each diploid genome, taking into consideration the genome composition of the wheat-rye translocation: an allohexaploid species carrying alien (rye) chromatin within its genome. This probe set was then used to detect differential expression of homoeologous transcripts in hexaploid wheat and the 2BS.2RL wheat-rye translocation, as well as in three diploid progenitors of hexaploid wheat and one diploid rye.

\section{MATERIALS AND METHODS}

Plant materials Near-isogenic lines (NILs) were developed by backcross introgression to form $\mathrm{BC}_{3} \mathrm{~F}_{3: 4}$ ('Coker $797^{\prime} * 4 /$ 'Hamlet') and differed in the presence or absence of $H 21$ on the $2 \mathrm{RL}$ derived from the diploid rye 'Chaupon' (S. cereale, $2 n=14$, 'R' genome) (Seo et al., 1997). 'Coker 797' is a non-2RL U.S. wheat germplasm and 'Hamlet' is a U.S. wheat germplasm derived from a $2 B S .2 R L$ wheatrye translocation (Sears et al., 1992). The presence of translocated 2RL was confirmed by FISH in a previous study (Lee et al., 2009). The NIL harboring 2RL (hereafter, 2BS.2RL), 'Chaupon', and hexaploid wheat $(2 n=6 x=$ 42) 'Chinese Spring' were used as custom array probes in this study. Three diploid progenitors $(2 n=14)$ of hexaploid wheat, T. urartu (Kyoto University seed stock accession no. KU199-6, 'A' genome), Aegilops speltoides (KU5727, 'B') and Ae. squarrosa (KU20-9, 'D'), were used as surrogates for the hexaploid wheat genome ('ABD').
Sequence preparation and a custom array design Consensus sequences for probe design were generated from local unigene clusters. EST and cDNA sequences from T. monococcum ('A' genome; 11,337 sequences), Ae. speltoides ('B'; 4,324), Ae. squarrosa ('D'; 142), Ae. tauschii ('D'; 142), T. aestivum ('ABD'; 1,067,304) and S. cereale ('R'; 10,858) were downloaded from NCBI (http:// www.ncbi.nlm.nih.gov). The sequences were assembled using CAP3 (Huang and Madan, 1999) with percent identity criteria of 89-94. Roughly $95 \%$ of the consensus sequences in the Affymetrix GeneChip Wheat Genome Array were covered by the unigene clusters. Two $60 \mathrm{bp}$ probes were designed from each consensus sequence. For $T$. aestivum, the probes were designed against the middle of the gene ( $1^{\text {st }}$ probe), and from $30 \mathrm{bp}$ upstream of the stop codon to within the 3'-UTR ( $2^{\text {nd }}$ probe). One of the two probes for each $T$. aestivum consensus sequence was designed to encompass the corresponding probe sequence of the Affymetrix GeneChip Wheat Genome Array. Probes for other species covered regions starting $60 \mathrm{bp}$ upstream of the stop codon ( $1^{\text {st }}$ probe), and from $30 \mathrm{bp}$ upstream of the stop codon to within the 3'-UTR $\left(2^{\text {nd }}\right.$ probe), giving a $30 \mathrm{bp}$ overlap between the $1^{\text {st }}$ and $2^{\text {nd }}$ probe sequences. Probe specificity was enhanced by including a species-specific SNP at or near the middle base position (Udall et al., 2006). Potential crosshybridization between probe sequences was checked by a reciprocal BLAST search (blastn). A total of 52,589 pairs of probes (5,518 'A'-, 2,439 'B'-, 225 'D'-, 39,060 'ABD'-, and 5,347 'R'-derived probes from T. monococcum, Ae. speltoides, Ae. squarrosa and Ae. tauschii, T. aestivum, and $S$. cereale, respectively) representing 52,589 genes were designed (Table 1, Supplementary Fig. S1). The probes were designed to have $\mathrm{T}_{\mathrm{m}}$ values between 75 and $85^{\circ} \mathrm{C}$. Random GC probes for monitoring hybridization efficiency and four corner fiducial controls were included

Table 1. Plant materials and genome-specific differential expression of transcripts

\begin{tabular}{|c|c|c|c|c|c|c|c|c|c|}
\hline \multirow{2}{*}{ Species } & \multirow{2}{*}{ Genome } & \multirow{2}{*}{$\begin{array}{c}\text { Total base (bp) of } \\
\text { consensus sequences }\end{array}$} & \multirow{2}{*}{$\begin{array}{l}\text { No. of } \\
\text { probes }\end{array}$} & \multicolumn{2}{|c|}{$\overline{\text { Genome-specific }}^{\mathrm{a}}$} & \multicolumn{2}{|c|}{ Chromatin-specific $^{b}$} & \multicolumn{2}{|c|}{ "Cross-hybridization ${ }^{\circ}$} \\
\hline & & & & $>1.96^{\mathrm{d}}$ & $>2.576$ & $>1.96$ & $>2.576$ & $<80 \%$ & $\geq 80 \%$ \\
\hline T. monococcum & AA & $3,213,847$ & 5,518 & 85 & 56 & & & 76 & $9(94.1)^{\mathrm{e}}$ \\
\hline Ae. speltoides & $\mathrm{BB}$ & $1,435,173$ & 2,439 & 42 & 24 & & & 39 & $3(96.3)$ \\
\hline $\begin{array}{l}\text { Ae. squarrosa \& } \\
\text { Ae. tauschii }\end{array}$ & DD & 106,992 & 225 & 2 & 1 & & & 2 & 0 \\
\hline S. cereale & $\mathrm{RR}$ & $2,730,048$ & 5,347 & 278 & 181 & 13 & 6 & 257 & $21(91.6)$ \\
\hline T. aestivum & $\mathrm{AABBDD}$ & $33,079,263$ & 39,060 & & & & & & \\
\hline Total & & & 52,589 & 407 & 262 & & & & \\
\hline
\end{tabular}

a Number of probes with corresponding genome-specific preferences compared to those with other species cDNAs.

b Number of 2RL-specific differentially expressed transcripts.

c Cross-hybridization of probes of genome-specific transcripts. Number of transcripts displaying $<80$ or $\geq 80 \%$ identity, obtained from reciprocal blastn alignments between probe sequences, are distinguished.

d The significance level of $\mathrm{Z}$ ratio.

e Avererage percent identity of those probes showing $\geq 80 \%$ identity. 
to assist with overlaying the grid on the image. The array was manufactured by NimbleGen (http://www. nimblegen.com) and synthesized on 12-plex arrays.

\section{Sample preparation, hybridization and data analy-} sis Seeds were planted in Sunshine Mix \#1 (Sun Gro, Canada) and maintained in a plant growth chamber with an average day/night temperature of $23 / 20^{\circ} \mathrm{C}, 14 \mathrm{~h}$ of light (12,000 LUX), and a relative humidity of $60 \%$ for 10 days. When plants reached the third leaf stage, the whole seedling including leaf and roots was harvested for RNA isolation. For array experiments, each seedling was frozen immediately in liquid nitrogen and then kept at $-80^{\circ} \mathrm{C}$ until RNA isolation. To obtain a diverse collection of RNAs, unstressed and drought-stressed (without irrigation for seven days) whole seedlings were used for RNA isolation. Drought-stressed plants showed clear symptoms of wilting when they reached seven days of treatment. Equimolar quantities of RNA from unstressed and stressed seedlings were pooled. Total RNA was isolated from seedlings using TRIzol reagent (Invitrogen, USA), according to the manufacturer's protocol. All glass and plastic labware including tubes, and a mortar and pestle, were treated overnight with $0.05 \%$ diethylpyrocarbonate and autoclaved the next day. Two independent biological replicates were used in separate hybridizations. Each biological replicate was a total RNA sample extracted from the whole tissue of two seedlings. cDNA synthesis, labeling and hybridization to 12 arrays (two arrays for each species sample: T. urartu, Ae. speltoides, Ae. squarrosa, 'Chinese Spring', 'Chaupon' and 2BS.2RL) were performed at GreenGene Biotech (Republic of Korea) (http://www.ggbio.com). To assess the reproducibility of the microarray analysis, we repeated the experiment twice with independently prepared total RNA. Probe-level summarization by robust multi-chip analysis (RMA) with a median polish algorithm implemented in NimbleScan was used for producing calls. RMA normalized data for each experiment were $\log _{10}$ transformed followed by standardization using $\mathrm{Z}$ score transformation equal to (value-average)/standard deviation to generate RMA data merged with $\mathrm{Z}$ scores. The $\mathrm{Z}$ ratio was used for calculating differences in hybridization values of probes across different samples. A $\mathrm{Z}$ ratio of \pm 1.96 was deduced as significant $(\mathrm{P}<0.05)$. Further data analysis and graph-plotting were done using Microsoft Excel. Expression data are available at NCBI Gene Expression Omnibus (GEO) under accession number GSE58678.

qRT-PCR Primers for quantitative real-time reverse transcription polymerase chain reaction (qRT-PCR) were designed to amplify one or more targeted polymorphisms within target contigs (Supplementary Table S1). Total RNA was isolated from unstressed seedlings as described above. RNA samples prepared for qRT-PCR were as follows: T. monococcum ('A' genome), Ae. speltoides ('B'), Ae. squarrosa ('D'), 'Coker 797' ('ABD'), 'Hamlet' (2BS.2RL) and 'Imperial' (S. cereale, $2 n=14$, 'R'). First-strand cDNA synthesis was accomplished using a Power cDNA synthesis kit (Intron Biotechnology, Republic of Korea). A control gene (Actin: accession no. AB181991) was used as an endogenous control for all assays. qRT-PCR was performed using Evagreen 2X qPCR MasterMix (Applied Biological Materials, Canada) and the CFX-96 system (Bio-Rad, USA). qRT-PCR products were analyzed using $1 \%$ agarose gel electrophoresis to ensure specific amplification of a single product. The $\Delta \Delta \mathrm{C}_{\mathrm{T}}$ method was used to measure the expression of a gene in the target genome relative to its expression in the control genome species from which the qRT-PCR primers were designed. 95\% confidence intervals were calculated to give error bars.

\section{RESULTS}

Differential expression of homoeologous genes in hexaploid wheat cDNAs from diploid progenitors ('A', 'B' and ' $\mathrm{D}$ ' genomes) of hexaploid wheat and diploid rye ('R') were used to empirically identify probes that distinguish transcripts derived from each genome in a $2 \mathrm{BS} .2 \mathrm{RL}$ wheat-rye translocation (2BS.2RL). In the case of ' $\mathrm{A}$ ' genome sequence-derived probes, 'A' genome cDNA rather than cDNAs from other species was expected to hybridize better to these probes. Eighty-five of the 5,518 probes derived from 'A' genome sequence (Supplementary Fig. S2A) preferentially hybridized to cDNA from the 'A' genome with $\mathrm{Z}$ ratios greater than 1.96 in all of the pairwise comparisons with genomes of other species (Supplementary Fig. S2B). These 85 transcripts were grouped into four distinct clusters based on their hybridization values in hexaploid wheat. In cluster one, 42 of the 85 transcripts showed no significant difference $(-1.96 \leq \mathrm{Z}$ ratio $\leq 1.96$ ) in expression between cDNA from the ' $\mathrm{A}$ ' genome and cDNAs from both the hexaploid wheat 'Chinese Spring' and 2BS.2RL (Fig. 1A, blue line in Fig. 1B). Cluster two contained 36 transcripts that showed significant differential expression $(>1.96)$ between transcripts from the 'A' genome and transcripts from the hexaploid genomes 'Chinese Spring' and 2BS.2RL (Fig. 1A, red line in Fig. 1B). The two transcripts in cluster three showed similar abundance in the ' $A$ ' genome and 'Chinese Spring', but significant variation in expression between the 'A' genome and 2BS.2RL. Conversely, the five transcripts in cluster four showed similar expression in the 'A' genome and 2BS.2RL but were differentially expressed in 'Chinese Spring'.

'B' and 'D' genome-derived probes were analyzed in the same manner as 'A' genome-derived probes. Forty-two of the 2,439 probes from the 'B' genome diploid progenitor (Supplementary Fig. S3A) showed significantly higher 
(A)

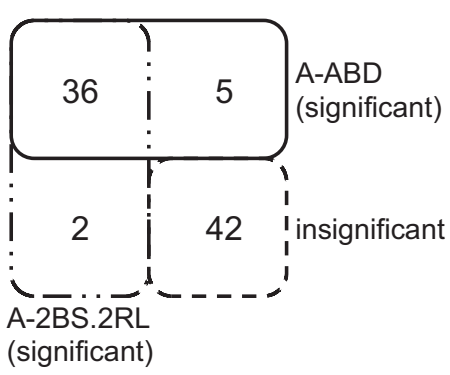

(B)

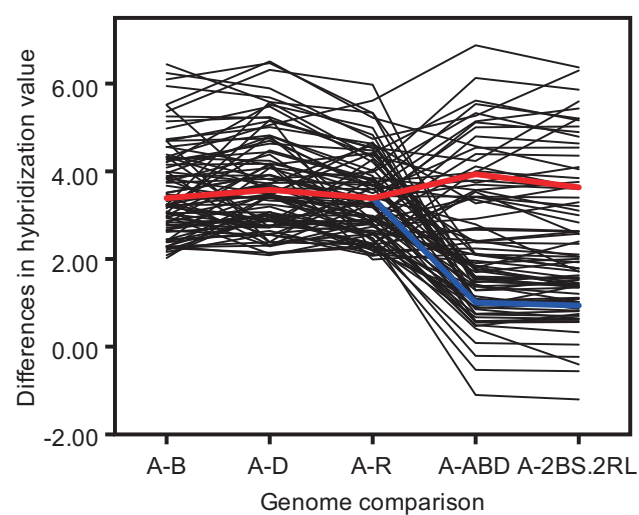

Fig. 1. Distinguishing 'A' genome-specific transcripts. (A) Eighty-five 'A' genome-specific transcripts were identified and grouped into four clusters according to their hybridization values in hexaploid wheat. The diagram represents clusters that show significant and insignificant differences in expression between cDNA from the 'A' genome and cDNA from either the 'Chinese Spring' or the 2BS.2RL genome. For example, 36 transcripts show significant differences $(Z$ ratio $>1.96$ ) for all of the pairwise comparisons of hybridization between cDNA from the 'A' genome and cDNAs from both the 'Chinese Spring' and 2BS.2RL genomes (red line in B). A-ABD and A-2BS.2RL represent $\mathrm{Z}$ ratios calculated by taking the difference between cDNAs from the two species. (B) Differences in hybridization values of 'A' genome-specific transcripts are illustrated. $x$-axis: comparison between cDNAs from pairs of species. A-B, A-D, A-R, A-ABD and A-2BS.2RL represent $\mathrm{Z}$ ratios calculated by taking the difference between cDNAs from each species. $y$-axis: $\mathrm{Z}$ ratio representing differences in hybridization value between samples. Blue and red lines indicate the mean value for probes that show $-1.96 \leq$ $\mathrm{Z}$ ratio $\leq 1.96$ (42 transcripts in cluster one), and $>1.96$ of $\mathrm{Z}$ ratio (36 in cluster two), respectively.

(A)

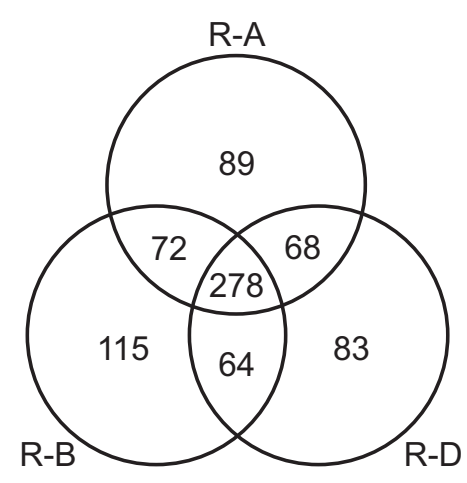

(B)

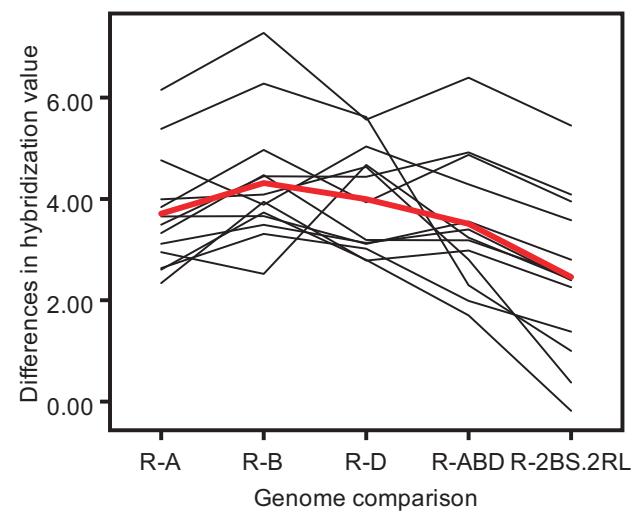

Fig. 2. Distinguishing ' $R$ ' genome-specific transcripts and identification of 2 RL-specific transcripts in the 2BS.2RL wheat-rye translocation. (A) Two hundred seventy-eight ' $R$ ' genome-specific transcripts are identified. The Venn diagram represents numbers of ' $R$ ' genome-derived probes that show preferential hybridization to rye transcripts. For example, 72 probes show differential expression both between cDNAs from ' $R$ ' and 'A' genomes, and between cDNAs from ' $R$ ' and 'B' genomes. R-A, R-B, and R-D represent $Z$ ratios calculated by taking the difference between cDNAs from pairs of species. (B) Differences in hybridization values of thirteen 2RL-specific transcripts are illustrated. $x$-axis: comparison between cDNAs from pairs of species. R-A, R-B, R-D, R-ABD, and R-2BS.2RL represent $\mathrm{Z}$ ratios calculated by taking the difference between cDNAs from species. $y$-axis: $\mathrm{Z}$ ratio representing differences in hybridization values between samples. Red line indicates the mean value for hybridizations.

hybridization efficiency ( $>1.96$ ) to cDNA from the ' $\mathrm{B}$ ' genome than to that from the 'A', ' $D$ ' and ' $R$ ' genomes (Supplementary Fig. S3B). These 42 transcripts were grouped into two distinct clusters based on their hybridization values in hexaploid wheat. Cluster one contained 12 transcripts that showed no significant difference $(-1.96 \leq \mathrm{Z}$ ratio $\leq 1.96)$ in transcript expression between 'B' genome and either hexaploid wheat 'Chinese Spring' or 2BS.2RL (Supplementary Fig. S3C, upper part of Venn diagram; blue line in Supplementary Fig. S3D). Cluster two contained 30 transcripts that showed significant differences (>1.96) in gene expression between 
the 'B' genome and the hexaploid genomes of 'Chinese Spring' and 2BS.2RL (Supplementary Fig. S3C, lower part of Venn diagram; red line in Supplementary Fig. $\mathrm{S} 3 \mathrm{D})$. Of the 225 probes derived from the ' $\mathrm{D}$ ' genome diploid progenitors (Ae. squarrosa and Ae. tauschii), two were found to preferentially hybridize to transcripts from the 'D' genome (Supplementary Fig. S4).

In addition, hexaploid wheat-derived probes whose genomic region is unclear ('A', ' $\mathrm{B}$ ' or ' $\mathrm{D}$ ' genome) were examined in hexaploid wheat cDNAs. Of the 39,060 transcripts, 2,116 showed significantly unequal hybridization between 'Chinese Spring' and 2BS.2RL (Supplementary Fig. S5).

\section{Differential expression of rye-derived transcripts} To discover preferential expression of transcripts from rye, 5,347 probes (Supplementary Fig. S6A) were generated in silico from diploid rye sequences. Of these, 278 probes showed preferential hybridization (greater than 1.96 of $\mathrm{Z}$ ratio from all of the pairwise comparisons of hybridization between cDNAs from rye and other species) to 'R' genome-derived transcripts (Fig. 2A, Supplementary Fig. S6B). In the 2BS.2RL wheat-rye translocation chosen, the long arm of rye chromosome 2 has replaced the long arm of wheat chromosome 2B (Friebe et al., 1990; Lee et al., 2009). Thirteen of the 278 transcripts showed significant differences ( $>$ 1.96) in expression between 2BS.2RL (cDNA from the 'ABD' genome and genomes of $2 \mathrm{RL}$ rather than $2 \mathrm{BL}$ ) and 'Chinese Spring' (cDNA from 'ABD' genome), representing 2RL-specific transcripts. Changes in hybridization values based on the $\mathrm{Z}$ ratio of these 2RL-specific transcripts across different genomes are illustrated in Fig. 2B. All genome-specific transcripts are summarized in Supplementary Table S2.

Validation of the array data A set of five genes was selected to verify the custom array results by qRTPCR. The transcripts were measured with three biological replicates where each biological replicate was a single seedling. Three technical replicates were performed for each biological replicate sample. The results of these highly replicated qRT-PCR experiments thus allow greater statistical power. Validation results for all five of the genes agreed with the array-based results in the direction of preferential expression (Supplementary Fig. S7).

Table 2. Description of the 106 genome-specific differentially expressed transcripts

\begin{tabular}{|c|c|c|c|c|c|c|c|c|}
\hline \multirow{2}{*}{ Probe identification } & \multirow{2}{*}{$\begin{array}{l}\text { Genome- } \\
\text { specific }\end{array}$} & \multicolumn{6}{|c|}{$\mathrm{Z}$ ratios $^{\mathrm{a}}$} & \multirow{2}{*}{ Functional annotation ${ }^{\mathrm{b}}$} \\
\hline & & $\mathrm{A}$ & $\mathrm{B}$ & $\mathrm{D}$ & $\mathrm{R}$ & $\mathrm{ABD}$ & 2BS.2RL & \\
\hline Tmonococcum_0397 ${ }^{\mathrm{c}}$ & $\mathrm{A}$ & & 4.2 & 5.5 & 5.0 & 0.9 & 1.4 & glycine-rich RNA-binding protein \\
\hline Tmonococcum_0485 & $\mathrm{A}$ & & 3.2 & 2.9 & 4.0 & 1.5 & 1.6 & VEF family protein \\
\hline Tmonococcum_0790 & A & & 4.6 & 4.1 & 4.4 & $\underline{5.6}$ & $\underline{5.2}$ & wall-associated receptor protein kinase family protein \\
\hline Tmonococcum_1378 & A & & 3.4 & 3.4 & 3.4 & 3.7 & $\underline{3.6}$ & peptide- $\mathrm{N}(4)-(\mathrm{N}$-acetyl-beta-glucosaminyl) asparagine amidase \\
\hline Tmonococcum_1456 & A & & 2.0 & 3.4 & 2.6 & $\underline{2.4}$ & $\underline{2.1}$ & serine carboxypeptidase-like \\
\hline Tmonococcum_1674 & $\mathrm{A}$ & & 2.2 & 2.6 & 2.8 & 0.9 & 1.0 & chain $\mathrm{A}, \beta$-D-glucan exohydrolase \\
\hline Tmonococcum_1985 & $\mathrm{A}$ & & 2.8 & 3.0 & 2.2 & 1.0 & 0.9 & homeobox-leucine zipper protein \\
\hline Tmonococcum_2230 & A & & 2.6 & 2.6 & 2.3 & 1.4 & 1.2 & pre-mRNA-processing factor 17 \\
\hline Tmonococcum_2343 & $\mathrm{A}$ & & 3.2 & 3.5 & 2.8 & 0.5 & 0.7 & auxin-responsive protein IAA10 \\
\hline Tmonococcum_2452 & $\mathrm{A}$ & & 5.9 & 5.7 & 4.8 & 0.9 & 1.1 & alanyl-tRNA expressed \\
\hline Tmonococcum_2771 & A & & 3.9 & 4.1 & 3.4 & $\underline{2.8}$ & 1.7 & chromatin complex subunit A101 \\
\hline Tmonococcum_2870 & $\mathrm{A}$ & & 3.0 & 3.1 & 2.6 & 0.7 & 0.7 & monoglyceride lipase-like \\
\hline Tmonococcum_2874 & $\mathrm{A}$ & & 3.2 & 3.2 & 3.0 & 1.4 & 1.4 & nucleolar complex protein 3 homolog \\
\hline Tmonococcum_2984 & $\mathrm{A}$ & & 4.7 & 5.0 & 4.6 & $\underline{3.3}$ & $\underline{3.7}$ & LysM domain containing protein \\
\hline Tmonococcum_3447 & $\mathrm{A}$ & & 2.2 & 2.1 & 2.3 & 0.1 & 0.0 & serine carboxypeptidase II-2 \\
\hline Tmonococcum_3475 & $\mathrm{A}$ & & 3.9 & 3.9 & 3.3 & $\underline{5.0}$ & $\underline{5.0}$ & ADP-ribosylation factor \\
\hline Tmonococcum_3625 & $\mathrm{A}$ & & 2.9 & 2.7 & 2.6 & $\underline{2.1}$ & 1.9 & malate dehydrogenase \\
\hline Tmonococcum_3713 & $\mathrm{A}$ & & 3.5 & 3.9 & 3.2 & 1.3 & 1.3 & far-red impaired response protein \\
\hline Tmonococcum_3993 & $\mathrm{A}$ & & 2.8 & 2.9 & 2.3 & 4.0 & $\underline{3.8}$ & b3 domain-containing protein \\
\hline Tmonococcum_4207 & A & & 2.2 & 3.0 & 2.6 & $\underline{3.4}$ & $\underline{3.2}$ & serine palmitoyltransferase 1 \\
\hline Tmonococcum_4317 & A & & 2.3 & 2.1 & 2.6 & 1.1 & $\overline{1.1}$ & LRR receptor-like serine/threonine-protein kinase RPK2 \\
\hline Tmonococcum_4379 & $\mathrm{A}$ & & 5.5 & 3.4 & 3.2 & 0.5 & 0.6 & far-red impaired response protein \\
\hline
\end{tabular}

Continued 
Table 2. Continued

\begin{tabular}{|c|c|c|c|c|c|c|c|c|}
\hline \multirow{2}{*}{ Probe identification } & \multirow{2}{*}{$\begin{array}{l}\text { Genome- } \\
\text { specific }\end{array}$} & \multicolumn{6}{|c|}{$\mathrm{Z}$ ratios $^{\mathrm{a}}$} & \multirow{2}{*}{ Functional annotation $^{\mathrm{b}}$} \\
\hline & & A & B & $\mathrm{D}$ & $\mathrm{R}$ & $\mathrm{ABD}$ & 2BS.2RL & \\
\hline Tmonococcum_4590 & $\mathrm{A}$ & & 3.0 & 3.4 & 4.7 & 1.5 & 1.4 & transcription initiation factor II subunit alpha-like \\
\hline Tmonococcum_4847 & $\mathrm{A}$ & & 2.3 & 2.4 & 2.3 & $\underline{2.7}$ & $\underline{2.6}$ & prolyl 4-hydroxylase subunit alpha-1 \\
\hline Tmonococcum_4883 & A & & 2.1 & 3.1 & 2.1 & $\underline{2.0}$ & 1.7 & 3-hydroxybutyryl- dehydrogenase \\
\hline Tmonococcum_5455 & A & & 4.4 & 3.8 & 3.7 & 3.3 & $\underline{2.8}$ & methionine s-methyltransferase \\
\hline Tmonococcum_5655 & A & & 4.3 & 3.6 & 3.6 & 3.8 & 3.6 & probable xyloglucan endotransglucosylase \\
\hline Tmonococcum_5657 & A & & 3.1 & 5.2 & 4.5 & 1.1 & 0.9 & delta-1-pyrroline-5-carboxylate synthetase \\
\hline Tmonococcum_5780 & A & & 3.7 & 3.3 & 3.2 & 1.8 & 1.5 & probable glutamate carboxypeptidase 2 -like isoform 1 \\
\hline Aspeltoides_0109 & $\mathrm{B}$ & 4.3 & & 2.7 & 2.0 & 3.3 & 3.4 & phosphoenolpyruvate/phosphate translocator 3 \\
\hline Aspeltoides_0770 & B & 3.2 & & 3.7 & 3.0 & 2.6 & $\underline{2.5}$ & PPR protein \\
\hline Aspeltoides_0927 & $\mathrm{B}$ & 3.8 & & 2.5 & 4.1 & 3.7 & $\underline{4.0}$ & chromophore lyase 3 \\
\hline Aspeltoides_1492 & $\mathrm{B}$ & 4.6 & & 4.3 & 4.1 & 5.0 & 4.7 & kinesin heavy \\
\hline Aspeltoides_1743 & $\mathrm{B}$ & 5.3 & & 6.3 & 6.6 & 3.4 & $\underline{3.0}$ & chalcone synthase \\
\hline Aspeltoides_2291 & $\mathrm{B}$ & 3.4 & & 3.4 & 2.5 & 3.8 & 3.7 & transcription factor IIA small \\
\hline Scereale_0093 & $\mathrm{R}$ & 2.2 & 2.9 & 2.3 & & 2.1 & 3.1 & protein WAX2 \\
\hline Scereale_0234 & $\mathrm{R}$ & 2.2 & 2.6 & 2.1 & & 2.1 & 2.2 & auxin-induced protein PCNT115 \\
\hline Scereale_0385 & $\mathrm{R}$ & 3.1 & 3.8 & 3.4 & & 3.6 & 3.5 & $\mathrm{NADH}$ dehydrogenase \\
\hline Scereale_0545 & $\mathrm{R}$ & 3.0 & 3.1 & 3.1 & & 2.8 & 2.7 & chain crystal structure of glutamine synthetase \\
\hline Scereale_0866 & $\mathrm{R}$ & 2.5 & 2.9 & 2.2 & & 1.6 & 1.5 & Rop guanine nucleotide exchange factor 1 \\
\hline Scereale_0933 & $\mathrm{R}$ & 2.0 & 2.0 & 2.7 & & 2.4 & 2.8 & galactosyltransferase \\
\hline Scereale_1150 & $\mathrm{R}$ & 5.5 & 2.5 & 5.4 & & 6.0 & 5.4 & Ras-related protein Rab-2-A \\
\hline Scereale_1159 & $\mathrm{R}$ & 2.2 & 2.3 & 2.3 & & 1.3 & 1.4 & actin \\
\hline Scereale_1213 & $\mathrm{R}$ & 4.2 & 3.7 & 3.2 & & 3.9 & 3.6 & GNAT family expressed \\
\hline Scereale_1316 ${ }^{\mathrm{c}}$ & $\mathrm{R}$ & 4.1 & 3.7 & 3.9 & & 4.3 & 3.9 & serine/threonine protein kinase \\
\hline Scereale_1384 & $\mathrm{R}$ & 3.5 & 2.3 & 2.0 & & 2.3 & 2.1 & ubiquitin-conjugating enzyme \\
\hline Scereale_1749 & $\mathrm{R}$ & 2.4 & 2.5 & 2.5 & & 2.0 & 1.8 & 6-phosphogluconate dehydrogenase \\
\hline Scereale_1804 & $\mathrm{R}$ & 2.8 & 2.8 & 3.1 & & 2.4 & 2.9 & J-domain protein \\
\hline Scereale_1835 & $\mathrm{R}$ & 4.5 & 4.7 & 4.8 & & 1.5 & 4.2 & (3R)-hydroxymyristoyl-[acyl-carrier-protein] dehydratase \\
\hline Scereale_1859 & $\mathrm{R}$ & 5.9 & 6.5 & 5.3 & & 6.0 & 5.8 & COP9 signalosome complex subunit 4 \\
\hline Scereale_1860 & $\mathrm{R}$ & 3.7 & 4.7 & 4.0 & & 4.4 & 3.9 & calvin cycle protein cp12 \\
\hline Scereale_1861 & $\mathrm{R}$ & 2.3 & 2.7 & 2.2 & & 2.3 & 2.2 & $40 \mathrm{~S}$ ribosomal protein $\mathrm{S} 3 \mathrm{a}$ \\
\hline Scereale_1953 & $\mathrm{R}$ & 2.4 & 2.0 & 2.4 & & 2.9 & 2.9 & HIPL1 protein \\
\hline Scereale_1955 & $\mathrm{R}$ & 2.4 & 3.8 & 2.7 & & 2.4 & 2.3 & cyclophilin B-B \\
\hline Scereale_1965 & $\mathrm{R}$ & 3.1 & 3.6 & 2.0 & & 1.1 & 2.8 & nudix hydrolase 8 \\
\hline Scereale_1999 & $\mathrm{R}$ & 3.2 & 4.3 & 4.4 & & 1.5 & 4.6 & dolichyl-diphosphooligosaccharide protein \\
\hline Scereale_2076 & $\mathrm{R}$ & 3.9 & 4.6 & 3.1 & & 1.2 & 4.1 & 6-phosphofructokinase 2 \\
\hline Scereale_2089 & $\mathrm{R}$ & 2.3 & 3.3 & 2.9 & & 3.3 & 3.1 & omega- 6 fatty acid endoplasmic reticulum \\
\hline Scereale_2124 & $\mathrm{R}$ & 5.1 & 5.7 & 5.1 & & 5.3 & 5.5 & cytochrome b5 reductase 4 \\
\hline Scereale_2133 & $\mathrm{R}$ & 3.8 & 5.0 & 5.0 & & 5.0 & 5.0 & protein chloroplastic \\
\hline Scereale_2196 & $\mathrm{R}$ & 2.9 & 3.1 & 2.3 & & 2.2 & 2.5 & calcium-dependent protein kinase \\
\hline Scereale_2218 & $\mathrm{R}$ & 2.1 & 2.8 & 2.1 & & 2.4 & 2.2 & long-chain-fatty-acid-CoA ligase 4 \\
\hline Scereale_2358 & $\mathrm{R}$ & 4.1 & 2.6 & 3.3 & & 3.3 & 2.8 & PER1A protein \\
\hline Scereale_2360 & $\mathrm{R}$ & 3.5 & 4.3 & 3.3 & & 4.1 & 4.1 & AP-1 complex subunit mu-1-I \\
\hline Scereale_2366 & $\mathrm{R}$ & 2.2 & 2.8 & 2.2 & & 2.5 & 2.5 & GDSL-motif lipase hydrolase family protein \\
\hline
\end{tabular}

Continued 
Table 2. Continued

\begin{tabular}{|c|c|c|c|c|c|c|c|c|}
\hline \multirow{2}{*}{ Probe identification } & \multirow{2}{*}{$\begin{array}{l}\text { Genome- } \\
\text { specific }\end{array}$} & \multicolumn{6}{|c|}{$\mathrm{Z}$ ratios $^{\mathrm{a}}$} & \multirow{2}{*}{ Functional annotation $^{\mathrm{b}}$} \\
\hline & & A & B & $\mathrm{D}$ & $\mathrm{R}$ & $\mathrm{ABD}$ & 2BS.2RL & \\
\hline Scereale_2376 & $\mathrm{R}$ & 5.6 & 2.4 & 4.5 & & 2.4 & 2.2 & plasma membrane atpase 1 \\
\hline Scereale_2813 & $\mathrm{R}$ & 2.5 & 3.7 & 2.5 & & 2.0 & 2.5 & ice recrystallization inhibition protein 1 precursor \\
\hline Scereale_2862 & $\mathrm{R}$ & 5.4 & 5.7 & 5.3 & & 5.9 & 5.5 & isco activase small isoform precursor \\
\hline Scereale_3449 & $\mathrm{R}$ & 2.5 & 2.7 & 2.7 & & 0.7 & 0.8 & protease do-like 14 \\
\hline Scereale_3458 & $2 \mathrm{RL}$ & 2.9 & 2.5 & 4.7 & & 3.2 & 2.4 & SNI1 \\
\hline Scereale_3743 & $\mathrm{R}$ & 2.4 & 2.3 & 2.6 & & 2.0 & 2.4 & RNA recognition motif-containing protein \\
\hline Scereale_3859 & $\mathrm{R}$ & 5.3 & 5.6 & 5.6 & & 5.3 & 5.0 & BURP domain-containing protein 10 \\
\hline Scereale_3897 & $\mathrm{R}$ & 2.8 & 3.9 & 2.4 & & 3.0 & 3.2 & disease resistance rpp13-like protein \\
\hline Scereale_3924 & $\mathrm{R}$ & 2.2 & 2.8 & 2.4 & & 2.9 & 2.6 & vesicle 2-related \\
\hline Scereale_4039 & $\mathrm{R}$ & 2.8 & 3.2 & 3.1 & & 2.9 & 3.0 & protein FAR1-related sequence 5 \\
\hline Scereale_4130 & $\mathrm{R}$ & 3.2 & 2.6 & 4.0 & & 0.3 & 0.2 & disease resistance protein RDL5/RF45 \\
\hline Scereale_4176 & $\mathrm{R}$ & 3.1 & 3.4 & 3.0 & & 3.3 & 3.2 & ferredoxin-NADP $(+)$ reductase \\
\hline Scereale_4228 ${ }^{\mathrm{c}}$ & $\mathrm{R}$ & 2.2 & 2.4 & 2.0 & & 2.0 & 2.1 & sucrose:fructan 6-fructosyltransferase \\
\hline Scereale_4260 & $\mathrm{R}$ & 2.6 & 2.9 & 2.3 & & 2.1 & 2.1 & lipid binding protein precursor \\
\hline Scereale_4371 & $\mathrm{R}$ & 4.1 & 4.1 & 3.9 & & 4.5 & 4.4 & senescence-associated protein \\
\hline Scereale_4386 & $\mathrm{R}$ & 4.8 & 6.3 & 5.3 & & 4.6 & 4.3 & phosphoprotein phosphatase inhibitor \\
\hline Scereale_4394 & $\mathrm{R}$ & 4.2 & 6.1 & 5.2 & & 4.9 & 4.6 & mate efflux family protein 9 \\
\hline Scereale_4406 & $\mathrm{R}$ & 3.3 & 3.6 & 3.9 & & 1.5 & 3.4 & mitochondrion protein \\
\hline Scereale_4547 & $2 \mathrm{RL}$ & 2.6 & 3.3 & 3.0 & & 2.0 & 1.4 & UDP-glucose 4-epimerase GEPI48 \\
\hline Scereale_4874 & $\mathrm{R}$ & 3.3 & 3.1 & 3.4 & & 3.7 & 3.4 & peroxidase 2 \\
\hline Scereale_4932 & $\mathrm{R}$ & 2.4 & 2.3 & 2.2 & & 3.5 & 3.5 & antimicrobial peptide MBP-1 \\
\hline Scereale_4954 & $\mathrm{R}$ & 3.0 & 5.2 & 4.9 & & 3.4 & 3.3 & carotenoid cleavage dioxygenase \\
\hline Scereale_5042 & $\mathrm{R}$ & 2.4 & 2.4 & 2.1 & & 2.6 & 2.7 & CASP-like protein sb05g025800 \\
\hline Scereale_5113 & $\mathrm{R}$ & 4.5 & 5.1 & 2.5 & & 2.0 & 2.6 & histone deacetylase hd2 \\
\hline Scereale_5143 & $\mathrm{R}$ & 2.6 & 3.6 & 2.9 & & 2.7 & 2.3 & protein auxin response 4 \\
\hline Scereale_5181 & $\mathrm{R}$ & 4.5 & 5.6 & 3.1 & & 5.1 & 5.5 & protein transparent testa 12 \\
\hline Scereale_5189 & $\mathrm{R}$ & 2.1 & 2.3 & 2.2 & & 1.8 & 1.6 & bZIP transcription factor superfamily \\
\hline Scereale_5241 & $\mathrm{R}$ & 3.7 & 3.7 & 3.6 & & 3.8 & 3.7 & low temprature induced-like protein \\
\hline Scereale_5293 & $\mathrm{R}$ & 3.6 & 4.4 & 4.2 & & 4.5 & 4.5 & 5 -adenylylsulfate reductase \\
\hline Scereale_5316 & $\mathrm{R}$ & 4.4 & 6.0 & 5.3 & & 5.4 & 5.3 & HGA6 \\
\hline Scereale_5324 & $\mathrm{R}$ & 2.3 & 2.8 & 3.9 & & 3.7 & 3.3 & histone-lysine N-methyltransferase ashr3 \\
\hline Scereale_5368 & $\mathrm{R}$ & 3.8 & 3.5 & 4.0 & & 4.0 & 3.8 & glutamyl-tRNA amidotransferase subunit \\
\hline Scereale_5431 & $\mathrm{R}$ & 2.8 & 3.6 & 2.5 & & 1.5 & 1.3 & multidomain cystatin \\
\hline Scereale_5448 & $\mathrm{R}$ & 3.9 & 2.8 & 2.3 & & 2.6 & 2.4 & dead-box atp-dependent RNA helicase 27 \\
\hline Scereale_5524 & $\mathrm{R}$ & 5.5 & 5.2 & 4.6 & & 4.8 & 4.9 & long chain acyl-synthetase 4 \\
\hline Scereale_5539 & $\mathrm{R}$ & 2.8 & 3.0 & 2.6 & & 2.8 & 2.9 & WRKY DNA-binding domain superfamily \\
\hline Scereale_5578 & $\mathrm{R}$ & 5.3 & 3.3 & 5.2 & & 0.9 & 3.2 & f-box protein pp2-a13 \\
\hline Scereale_5641 & $\mathrm{R}$ & 4.7 & 3.8 & 3.7 & & 3.1 & 3.2 & ankyrin-1 \\
\hline Scereale_5672 & $\mathrm{R}$ & 3.2 & 2.9 & 2.9 & & 3.1 & 3.0 & bZIP protein \\
\hline Scereale_5850 & $\mathrm{R}$ & 2.5 & 2.6 & 3.4 & & 3.1 & 3.0 & sucrose synthase 1 \\
\hline Scereale_5919 & $\mathrm{R}$ & 3.5 & 2.6 & 2.7 & & 3.0 & 2.6 & polyadenylate-binding protein 2 \\
\hline
\end{tabular}

\footnotetext{
${ }^{a} \mathrm{Z}$ ratio between cDNA from the corresponding species of the probe and cDNA from other species. Significant differences in hybridization values in hexaploid wheat are underlined.

b BLAST results against barley gene models are displayed.

c Validation of transcript expression was performed using qRT-PCR (Supplementary Fig. S7).
} 
Identification of the transcripts A total of 407 transcripts showed differential expression among the homoeologs from the different wheat progenitors and rye genomes. Of these transcripts, $106(26 \%)$ were annotated using blastx and tblastx against non-redundant protein sequences and high-confidence barley gene models (http://webblast.ipk-gatersleben.de/barley), respectively (Table 2). BLAST hits were considered significant only if both of the search criteria, $\geq 70 \%$ identity and a minimum of 30 bp coverage, were satisfied.

\section{DISCUSSION}

A higher percentage (5.0\%) of rye sequence-derived probes were identified as rye-specific transcripts when compared to genome-specific transcripts from diploid progenitors (0.9-1.7\%). Higher nucleotide sequence similarity among diploid progenitors than between wheat and rye orthologs may have affected the identification rate of diploid genome-specific transcripts.

Among genome-specific differentially expressed transcripts, several interesting genes were identified. Serine carboxypeptidase-like protein encoding genes detected by the 'A' genome-specific probes (Tmonococcum_1456 \& 3447 ) have been shown to be involved in plant growth and development via brassinosteroid signaling ( $\mathrm{Li}$ et al., 2001) and disease resistance (Dixon, 2001; Mugford et al., 2009). Potential roles in secondary metabolism and resistance have been described for a serine carboxypeptidase-like acyltransferase in oat, a close relative of wheat and rye in the Pooideae (Mugford et al., 2009). These genes are potential candidates for characterizing resistance traits of the 2BS.2RL wheat-rye translocation. Another 'A' genome-specific gene was that encoding $\beta$-Dglucan exohydrolase, which is involved in the degradation and reorganization of cell wall polysaccharides (Minic and Jouanin, 2006). Diverse functions have been suggested for $\beta$-glucosidase during plant development because of its broad specificity for glycosyl residues (Hrmova et al., 2002). $\beta$-glucosidase is one of the proteins detected by two-dimensional gel electrophoresis whose intensity varied significantly between Hessian fly-infested and noninfested 2BS.2RL wheat-rye translocations (Lee et al., 2011). It is also possible that $\beta$-D-glucan exohydrolase (chain A) detected in this study (Tmonococcum_1674) may function in various ways. LRR receptor-like serine/ threonine-protein kinase RPK2-like (also called receptorlike protein kinase 2) is a key regulator of anther development in plants (Mizuno et al., 2007; Nodine and Tax, 2008). A transcript (Tmonococcum_4317) differentially expressed in the 'A' genome was identified as encoding the RPK2-like protein.

Two 2RL-specific transcripts, Scereale_3458 and Scereale_4547, are annotated under given BLAST criteria. One of them is SNI1, suppressor of npr1-1, inducible, which functions as a negative regulator of systemic acquired resistance in plant basal defense (Durrant et al., 2007; Kim et al., 2012). The other gene is annotated as UDP-glucose 4-epimerase GEPI48-like but its function has not yet been well studied. Several interesting rye genome-specific transcripts were detected in this study. These rye-specific probes may be applicable to other wheat-rye translocations such as 1BL.1RS. Another annotated gene (Scereale_1316) is classified as a serine/threonine kinase gene, a key member of powdery mildew resistance to wheat (Cao et al., 2011). Wheat-rye translocation in the form of $2 \mathrm{BS} .2 \mathrm{RL}$ shows powdery mildew resistance (Lee et al., 2009). Rye is more tolerant to frost and drought than is wheat (http://www.gramene.org/ species/secale/rye_intro.html). A transcript detected by the probe Scereale_2813 matched the ice recrystallization inhibition protein (IRIP) 1. Transgenic Arabidopsis harboring Deschampsia antarctica E. Desv. IRIP showed an elevated recrystallization inhibition activity (John et al., 2009). Scereale_0093 was identified as a WAX2 encoding gene from Brachypodium distachyon. The Arabidopsis mutant wax2 showed alterations in both cuticle membrane and cuticular waxes (Chen et al., 2003). Cuticle forms a protective covering over the outermost surface of the plant and thus functions as a barrier to water loss under dehydration and drought (Goodwin and Jenks, 2005). Both of the transcripts Scereale_2813 and Scereale_0093 showed significant 'R' genome preferential expression in diploid and hexaploid genomes. These genes may have an impact on functionally important ryederived traits including cold and drought tolerance levels and are potentially valuable resources for further studies. A disease resistance protein, RDL5/RF45, that is specified by Scereale_4130 is not functionally well characterized. Since disease resistance traits are desirable targets that could be selected and transferred to wheat in the form of wheat-rye chromosomal translocations, this gene is also a suitable candidate for further research.

When homoeolog-specific probes were applied to cDNAs from the hexaploid wheat 'Chinese Spring' and the 2BS.2RL wheat-rye translocation, the expression of some of the transcripts was found to be significantly higher or lower in the hexaploid wheat than in the diploid progenitor. Unequal expression of homoeologous genes and changes in homoeolog bias have been observed in polyploid species (Nomura et al., 2005; Hovav et al., 2008). We can speculate that some specific genome preferential transcripts exhibit expression changes in hexaploid wheat including chromosome translocation lines.

The target genomic region for over two thousand transcripts that were identified as preferentially hybridizing either 'Chinese Spring' or 2BS.2RL remains unknown. Elucidation of the genome sequences of common wheat 
(Brenchley et al., 2012; International Wheat Genome Sequencing Consortium, 2014) and its progenitors (Jia et al., 2013; Ling et al., 2013; Luo et al., 2013), along with identification and mapping of genic regions will be necessary to verify accurately the genomic source of these transcripts.

We have developed an array platform for detecting genome-specific transcripts using hybridization-based probes. This platform provides no easily flexible probes that are barcoded on the array. However, rapid probing of differentially expressed genes gives a clear picture of overall transcript compositions. It can provide a substantial amount of information as a preliminary step to characterize uncharacterized transcripts in target plant samples such as wheat-rye translocations. Our results also give valuable information including sequence polymorphisms that could be added to increased next-generation sequencing data and individual genome structure, and thus represent useful resources to understand the complex hexaploid genome.

The authors are grateful to Kankshita Swaminathan for critical reading of the manuscript. This work was supported by a Korea University Grant (T.G.L.), the Next-Generation BioGreen 21 Program (Plant Molecular Breeding Center No. PJ008031), Rural Development Administration, Republic of Korea (Y.W.S.), and the National Research Foundation of Korea (NRF) grant funded by the Korea government (MSIP) (No. 2012M2A2A6035566) (Y.W.S.).

\section{REFERENCES}

Brenchley, R., Spannagl, M., Pfeifer, M., Barker, G. L. A., D'Amore, R., Allen, A. M., McKenzie, N., Kramer, M., Kerhornou, A., Bolser, D., et al. (2012) Analysis of the bread wheat genome using whole-genome shotgun sequencing. Nature 491, 705-710.

Cao, A., Xing, L., Wang, X., Yang, X., Wang, W., Sun, Y., Qian, C., Ni, J., Chen, Y., Liu, D., et al. (2011) Serine/threonine kinase gene $S t p k-V$, a key member of powdery mildew resistance gene Pm21, confers powdery mildew resistance in wheat. Proc. Natl. Acad. Sci. USA 108, 7727-7732.

Chen, X., Goodwin, S. M., Boroff, V. L., Liu, X., and Jenks, M. A. (2003) Cloning and characterization of the WAX2 gene of Arabidopsis involved in cuticle membrane and wax production. Plant Cell 15, 1170-1185.

Coram, T. E., Wang, M., and Chen, X. (2008) Transcriptome analysis of the wheat-Puccinia striiformis f. sp. tritici interaction. Mol. Plant Pathol. 9, 157-169.

Devos, K. M., Moore, G., and Gale, M. D. (1995) Conservation of marker synteny during evolution. Euphytica 85, 367-372.

Dixon, R. A. (2001) Natural products and plant disease resistance. Nature 411, 843-847.

Durrant, W. E., Wang, S., and Dong, X. (2007) Arabidopsis SNI1 and RAD51D regulate both gene transcription and DNA recombination during the defense response. Proc. Natl. Acad. Sci. USA 104, 4223-4227.

Friebe, B., Hatchett, J. H., Sears, R. G., and Gill, B. S. (1990) Transfer of Hessian fly resistance from 'Chaupon' rye to hexaploid wheat via a $2 \mathrm{BS} / 2 \mathrm{RL}$ wheat-rye chromosome translocation. Theor. Appl. Genet. 79, 385-389.

Friebe, B., Jiang, J., Raupp, W. J., McIntosh, R. A., and Gill, B. S. (1996) Characterization of wheat-alien translocations conferring resistance to diseases and pests: current status. Euphytica 91, 59-87.

Goodwin, S. M., and Jenks, M. A. (2005) Plant cuticle function as a barrier to water loss. In: Plant Abiotic Stress (eds.: M. A. Jenks and P. M. Hasegawa) pp. 14-36. Blackwell Publishing, Oxford.

Graybosch, R. A. (2001) Uneasy unions: quality effects of rye chromatin transfers to wheat. J. Cereal Sci. 33, 3-16.

Hatchett, J. H., Sears, R. G., and Cox, T. S. (1993) Inheritance of resistance to Hessian fly in rye and in wheat-rye translocation lines. Crop Sci. 33, 730-734.

Hovav, R., Udall, J. A., Chaudhary, B., Rapp, R., Flagel, L., and Wendel, J. F. (2008) Partitioned expression of duplicated genes during development and evolution of a single cell in a polyploid plant. Proc. Natl. Acad. Sci. USA 105, 61916195.

Hrmova, M., De Gori, R., Smith, B. J., Fairweather, J. K., Driguez, H., Varghese, J. N., and Fincher, G. B. (2002) Structural basis for broad substrate specificity in higher plant $\beta$-D-glucan glucohydrolases. Plant Cell 14, 10331052.

Huang, X., and Madan, A. (1999) CAP3: A DNA sequencing assembly program. Genome Res. 9, 868-877.

International Wheat Genome Sequencing Consortium (2014) A chromosome-based draft sequence of the hexaploid bread wheat (Triticum aestivum) genome. Science 345, 1251788.

Jia, J., Zhao, S., Kong, X., Li, Y., Zhao, G., He, W., Appels, R., Pfeifer, M., Tao, Y., Zhang, X., et al. (2013) Aegilops tauschii draft genome sequence reveals a gene repertoire for wheat adaptation. Nature 496, 91-95.

John, U. P., Polotnianka, R. M., Sivakumaran, K. A., Chew, O., Mackin, L., Kuiper, M. J., Talbot, J. P., Nugent, G. D., Mautord, J., Schrauf, G. E., et al. (2009) Ice recrystallization inhibition proteins (IRIPs) and freeze tolerance in the cryophilic Antarctic hair grass Deschampsia antarctica E. Desv. Plant Cell Environ. 32, 336-348.

Kim, H. S., Park, H. C., Kim, K. E., Jung, M. S., Han, H. J., Kim, S. H., Kwon, Y. S., Bahk, S., An, J., Bae, D. W., et al. (2012) A NAC transcription factor and SNI1 cooperatively suppress basal pathogen resistance in. Nucleic Acids Res. 40, 91829192

Kishii, M., Delgado, R., Rosas, V., Cortes, A., Cano, S., Sanchez, J., and Mujeeb-Kazi, A. (2008) Exploitation of genetic resources through wide crosses. In: Proc. Int. Symp. on Wheat Yield Potential: Challenges to International Wheat Breeding (eds.: M. P. Reynolds, J. Pietragalla, and H-J. Braun), pp. 120-125. CIMMYT, Mexico, D. F.

Knackstedt, M. A., Sears, R. G., Rogers, D. E., and Lookhart, G. L. (1994) Effects of T2BS.2RL wheat-rye translocation on bread making quality in wheat. Crop Sci. 34, 1066-1070.

Laudencia-Chingcuanco, D., Ganeshan, S., You, F., Fowler, B., Chibbar, R., and Anderson, O. (2011) Genome-wide gene expression analysis supports a developmental model of low temperature tolerance gene regulation in wheat (Triticum aestivum L.). BMC Genomics 12, 299.

Lee, T. G., Hong, M. J., Johnson, J. W., Bland, D. E., Kim, D. Y., and Seo, Y. W. (2009) Development and functional assessment of EST-derived 2RL-specific markers for 2BS.2RL translocations. Theor. Appl. Genet. 119, 663-673.

Lee, T. G., Lee, Y. J., Kim, D. Y., and Seo, Y. W. (2010) Comparative physical mapping between wheat chromosome arm $2 \mathrm{BL}$ and rice chromosome 4. Genetica 138, 1277-1296. 
Lee, T. G., Johnson, J. W., and Seo, Y. W. (2011) Comparison of proteomes between wheat-rye translocations and their recurrent parents. Russ. J. Plant Physiol. 58, 703-714.

Lee, T. G., Kim, D. Y., Johnson, J. W., and Seo, Y. W. (2013) A genome-wide analysis of transcripts in a $2 \mathrm{BS} .2 \mathrm{RL}$ wheat-rye translocation during Hessian fly infestation. Genes Genom. 35, 795-803.

Li, J., Lease, K. A., Tax, F. E., and Walker, J. C. (2001) BRS1, a serine carboxypeptidase, regulates BRI1 signaling in Arabidopsis thaliana. Proc. Natl. Acad. Sci. USA 98, 59165921.

Ling, H. Q., Zhao, S., Liu, D., Wang, J., Sun, H., Zhang, C., Fan, H., Li, D., Dong, L., Tao, Y., et al. (2013) Draft genome of the wheat A-genome progenitor Triticum urartu. Nature 496, 87-90.

Luo, M. C., Gu, Y. Q., You, F. M., Deal, K. R., Ma, Y., Hu, Y., Huo, N., Wang, Y., Wang, J., Chen, S., et al. (2013) A 4gigabase physical map unlocks the structure and evolution of the complex genome of Aegilops tauschii, the wheat Dgenome progenitor. Proc. Natl. Acad. Sci. USA 110, 79407945.

McKendry, A. L., Tague, D. N., and Ross, K. (2001) Comparative effects of 1BL.1RS and 1AL.1RS on soft red winter wheat milling and baking quality. Crop Sci. 41, 712-720.

Minic, Z., and Jouanin, L. (2006) Plant glycoside hydrolases involved in cell wall polysaccharide degradation. Plant Physiol. Biochem. 44, 435-449.

Mizuno, S., Osakabe, Y., Maruyama, K., Ito, T., Osakabe, K., Sato, T., Shinozaki, K., and Yamaguchi-Shinozaki, K. (2007) Receptor-like protein kinase 2 (RPK 2 ) is a novel factor controlling anther development in Arabidopsis thaliana. Plant
J. 50, 751-766

Mugford, S. T., Qi, X., Bakht, S., Hill, L., Wegel, E., Hughes, R. K., Papadopoulou, K., Melton, R., Philo, M., Sainsbury, F., et al. (2009) A serine carboxypeptidase-like acyltransferase is required for synthesis of antimicrobial compounds and disease resistance in oats. Plant Cell 21, 2473-2484.

Naranjo, T., and Fernandez-Rueda, P. (1991) Homoeology of rye chromosome arms to wheat. Theor. Appl. Genet. 82, 577586.

Nodine, M. D., and Tax, F. E. (2008) Two receptor-like kinases required together for the establishment of Arabidopsis cotyledon primordia. Dev. Biol. 314, 161-170.

Nomura, T., Ishihara, A., Yanagita, R. C., Endo, T. R., and Iwamura, H. (2005) Three genomes differentially contribute to the biosynthesis of benzoxazinones in hexaploid wheat. Proc. Natl. Acad. Sci. USA 102, 16490-16495.

Sears, R. G., Hatchett, J. H., Cox, T. S., and Gill, B. S. (1992) Registration of Hamlet, a Hessian fly resistant red winter wheat germplasm. Crop Sci. 32, 506.

Seo, Y. W., Johnson, J. W., and Jarret, R. L. (1997) A molecular marker associated with the H21 Hessian fly resistance gene in wheat. Mol. Breed. 3, 177-181.

Udall, J. A., Swanson, J. M., Nettleton, D., Percifield, R. J., and Wendel, J. F. (2006) A novel approach for characterizing expression levels of genes duplicated by polyploidy. Genetics 173, 1823-1827.

Yu, Y., Guo, G., Lv, D., Hu, Y., Li, J., Li, X., and Yan, Y. (2014) Transcriptome analysis during seed germination of elite Chinese bread wheat cultivar Jimai 20. BMC Plant Biol. 14: 20 . 